\section{Maximal acid output}

R. Tauber und F. H. Perschel

Institut für Laboratoriumsmedizin, Klinische Chemie und Pathobiochemie, Charité - Universitätsmedizin Berlin Campus Virchow-Klinikum, Berlin, Deutschland

Synonym(e) MAO; maximale Säuresekretion

Englischer Begriff maximal acid output

Definition Die maximale Säuresekretion entspricht der gesamten Menge der mit dem Magensaft während 60 Minuten nach Stimulation sezernierten Säure (HCI).

Beschreibung Die maximale Säuresekretion (MAO) dient in der Magensekretionsanalyse zusammen mit der basalen
Säuresekretion (BAO) und dem ,peak acid output“ (PAO) der Diagnostik einer Hyper- (z. B. bei Zollinger-EllisonSyndrom) oder einer Hyposekretion des Magens (z. B. bei chronisch atrophischer Gastritis). Gemessen wird die innerhalb der ersten Stunde nach Gabe von $6 \mu \mathrm{g}$ Pentagastrin pro kg KG sezernierte $\mathrm{H}^{+}$-Menge durch Titration mit $\mathrm{NaOH}$. Der Einsatz von $>$ Histamin und Analoga zur Stimulation ist wegen der ausgeprägteren Nebenwirkungen seit der Verfügbarkeit von Pentagastrin nicht mehr üblich (s. a. > Magensekretionsanalyse).

\section{Literatur}

Metz DC, Starr JA (2000) A retrospective study of the usefulness of acid secretory testing. Aliment Pharmacol Ther 14:103-111 